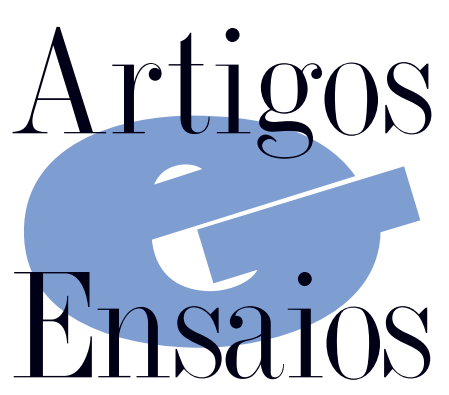

\section{O CINEMA E 0 CAMPO PERCEPTIVO DA CIÊNCIA}

\section{Márcio Barreto}

O cinema é resultado da união entre velocidade e fotografia, ideia formulada por Walter Benjamin (1) segundo a qual o cinema já estava contido virtualmente na fotografia. No dia22 de março de 1895, os irmãos Lumière exibiram o cinematógrafo na Sociedade para o Desenvolvimento da Ciência de Paris, quando o filme A saída dos operários da fábrica Lumière (La sortie de l'usine Lumière à Lyon) foi mostrado pela primeira vez. A chegada do trem à Estação Ciotat, filme dos irmãos Auguste e Louis Lumière de quarenta e cinco segundos de duração, teve sua primeira (2) exibição pública em Paris a 28 de dezembro de 1895 e marcou o encontro da locomotiva, a imagem da velocidade tecnológica, com a cinematografia, a velocidade da imagem fotográfica.

Relatos da primeira exibição de A chegada do trem à Estação Ciotat retratam um público totalmente afetado pela imagem do trem que se aproximava vertiginosamente do fundo para o primeiro plano, rumo ao limite esquerdo do campo. "Estamos aqui em plena inauguração daquilo que Gilles Deleuze chamou de imagem-movimento, as pessoas correndo todas para o fundo da sala num ato reflexo diante da imagem do trem chegando à estação" (3).

"[...] a percepção não deve nada àquilo que nós sabemos de outro modo sobre o mundo, sobre os estímulos, tais como a física os descreve, sobre os órgãos dos sentidos, tais como a biologia os descreve. Em primeiro lugar, ela não se apresenta como um acontecimento no mundo ao qual se possa aplicar, por exemplo, a categoria de causalidade, mas a cada momento como uma recriação ou uma reconstituição do mundo." (4)
A percepção é uma experiência incompleta que abre horizontes de novas experiências, mas tal incompletude não impede a certeza da presença do que é percebido.

A rigor, a experiência da coisa no esboço reduz-se à possibilidade de prosseguir a experiência, de multiplicar as percepções com a garantia de que não haverá fim. [...] A percepção teria, assim, um caráter transcendente, no sentido que excede as potencialidades que aparecem num primeiro plano que não esgotam a realidade daquilo que é percebido. Em suma, a coisa percebida não se apresenta ela mesma, conforme suas características próprias, naquilo que a manifesta: o esboço, ao mesmo tempo, desvenda e dissimula a coisa. Quanto à coisa, ela aparece como sua ausência, se apresenta como inapreensível. (5)

O cinema é capaz de operar a transcendência do espectador numa experiência que excede o vivido mental, a representação e o campo perceptivo, aquilo que a inteligência não esgota, mas que a intuição, no sentido bergsoniano do termo, consegue assegurar sua realidade. Os filmes de Harun Farocki desenvolvem essa potencialidade da imagem-tempo: uma vez que o espectador assiste ao filme Die schöpfer der einkaufswelten (Os criadores dos mundos dos shoppings: 2011), jamais irá a um shopping center com o mesmo olhar de antes dessa experiência cinematográfica. O que fez Werner Herzog no recente The cave offorgottendreams (A caverna dos sonhos esquecidos: 2010) é prova de que o cinema é estímulo para inesgotáveis níveis de percepção: O posfácio é uma espécie de sinestesia temporal, pois nos faz perceber, ainda em estado de encantamento dos olhos pela viagem que as imagens em três dimensões nos levam a trinta mil anos no passado, a tecnociência no presente.

Desde o início da era moderna, tecnociência e política se 


\section{Artigos $~ E$ Ensaios}

tornaram cada vez mais indissociáveis, na mesma medida em que aumentou a nossa capacidade de manipular a matéria em um nível inacessível ao senso comum e, no limite, à própria imaginação humana. A experiência do tempo foi particularmente sensível a esse processo. Por um lado, foi dividida entre um tempo quantitativamente mensurável (o tempo-medida) e um tempo qualitativo vivido (o tempo-duração). Por outro lado, este último foi crescentemente reduzido a um tempo psicológico e, portanto, insignificante para a física, tal como ficou evidenciado na indiferença de Einstein diante do esforço de Bergson no debate de 1922 para encontrar a metafísica que envolve a teoria da relatividade. Privada de sua metafísica, a teoria se restringiu a uma sofisticada espacialização do tempo que é inacessível à nossa percepção. Estaria na arte, especificamente no cinema, a via que reconduziria a metafísica na percepção da ciência? Filmes que contribuem com a divulgação da ciência são comuns em artigos publicados em revistas indexadas, em jornais impressos e eletrônicos, em blogs e mesmo em conversas informais. Nova (6) distinguiu esses filmes como: documentários, reconstruções de momentos marcantes da história da ciência, filmes de biografias de cientistas, filmes nos quais cientistas são imersos numa trama ficcional, ficções científicas, entre outros. Seja qual for a categoria em que o filme se enquadre, "a ciência é geralmente retratada no cinema como civilizadora, progressiva, racional, e neutra. O conhecimento científico é visto como algo apolítico, não dogmático, inteiramente fundamentado e comprovado, mas perigoso." (7)

No entanto, as múltiplas relações entre ciência, política, economia e sociedade devem ultrapassar a ingênua correspondência biunívoca entre os conceitos científicos abordados num filme e sua função pedagógica na percepção pública da ciência. Confundindo a tela de projeção com a retina do espectador, o cinema permite que a ciência seja discutida dentro e fora dos limites de suas fronteiras habituais, e que a percepção de quem é arrebatado pela imagem em movimento vá além daquela que o senso comum adota a partir dos meios tradicionais de divulgação científica e dos espaços de educação formal, tal como acontece em Como se pode ver (Wiemansieht: 1985) de Harun Farocki.

Para Deleuze (8), a tela de projeção do filme é a membrana cerebral onde se afrontam imediatamente, diretamente, o passado e o futuro, o interior e o exterior, sem distância designável, independentemente de qualquer ponto fixo. As imagens cinematográficas nos afetam instaurando em nós a topologia do tempo do filme, um tempo tão real quanto artificial, criado na percepção do espectador através da mistura de fotogramas que se sucedem em sua retina. 0 diretor de um filme tem em mãos o poder de nos afetar com a sucessão de imagens que constrói. O trabalho de um diretor de cinema refinado, como afirma o cineasta russo Andrei Tarkovski (9), é o de "esculpir o tempo", assim como o escultor toma um bloco de mármore e elimina tudo o que não faz parte de sua futura obra. Quando esse refinamento do olhar se derrama sobre a ciência, o espectador passa a enxergá-la sem seus estereótipos habituais.

Vênus negra (Vénus noire: França, 2011), dirigido pelo tunisiano Abdellatif Kechiche, possui várias entradas, mas se tomarmos a que tem o fio condutor da ciência, somos surpreendidos por uma espécie de relativização da verdade científica, pelas vacilações do método científico e pelas subordinações da ciência às questões supostamente alheias aos seus domínios de maneira visceral.

A primeira cena é arrebatadora, especialmente porque o filme é bastante fiel aos fatos históricos no quais se baseou: numa palestra sobre anatomia proferida em 1817 na Real Academia de Medicina (França), um modelo do corpo da sul-africana Saartjie Baartman (brilhantemente interpretada por Yahima Torres), feito em gesso antes que ela fosse desintegrada pelas lâminas dos cientistas, é exibido à comunidade científica como prova dos atributos físicos de uma mulher negra serem semelhantes aos de macacos dos quais se originaram, uma prática usada para defender a superioridade dos brancos, os quais teriam origem diferente, mais distante dos símios do que a dos negros. Diante do corpo de Saartjie, o anatomista Georges Cuvier diz que jamais tinha visto uma cabeça humana tão parecida com a dos macacos. Uma plateia composta por cientistas aplaude a constatação.

Alardeada como prática puramente objetiva e quantitativa, a ciência é percebida pelo senso comum como isenta de valores mercadológicos, preconceitos ou ideologias. No entanto, seu caráter absoluto e verdadeiro é colocado em xeque no filme de Kechiche. Uma vez reconhecido o giro falso do discurso banalizado sobre a ciência, o espectador perde sua ingenuidade em relação ao tema de maneira irreversível, experiência viva de um espectador que vai além da pura análise do conteúdo científico de um filme.

Artigos publicados em revistas de prestígio acadêmico, como o de Cormick (10), abordam de maneira interessante 


\section{Artigos \& Ensaios}

as relações entre ciência, cinema e sociedade, mas não vão além da pura análise, diferentemente do que faz Dutra (11) ao nos chamar a atenção para um travelling de 2001 - Uma odisseia no espaço (2001 - a space odyssey: Stanley Kubrick, 1968). "Seguindo a câmera somos introduzidos no novo ambiente penetrando uma janela envidraçada e transparente cujo formato lembra uma tela de cinema". A travessia sugere a passagem do sonho tecnológico para o pesadelo que se inicia com o defeito do computador HAL, como se um novo filme ali começasse com a tecnociência fugindo do controle dos que nela depositaram toda sua confiança.

Esta sutileza na narrativa do filme de Kubrick tem tanta força quanto a escada espiral de Gattaca:a experiência genética (Gattaca, Andrew Niccol, 1997): muito semelhante ao modelo da dupla hélice do DNA, a escada simboliza a passagem da diferença de classes para o plano molecular, mas em nenhum momento é mencionada como tal: é a percepção do espectador que, de forma consciente ou subliminar, realiza a analogia. Resultado da combinação entre teoria e prática laboratorial, a ciência moderna surge com o método de interrogar a natureza até que ela "confesse" suas leis. Neste sentido, a descoberta de Newton da lei da atração gravitacional na segunda metade do século XVII significou o coroamento da ciência moderna.

As origens metafísicas da ciência moderna, como o hermetismo propagado por Giordano Bruno, a busca de Newton para ouvir o discurso de Deus cifrado na linguagem matemática das leis da natureza e os princípios sagrados da alquimia foram gradualmente esquecidos em favor da domesticação dos fenômenos da natureza, criando condições favoráveis ao desenvolvimento do capitalismo, transferindo o que havia de sagrado nos primórdios da ciência para o fetiche da mercadoria.

O alcance da síntese newtoniana, no sentido da instauração de uma visão utilitarista da ciência, foi impressionante: por um lado, permitiu à humanidade avanços vertiginosos no que diz respeito ao seu sucesso para habitar o planeta, mas representou também, por outro lado, o descolamento da prática científica de outras dimensões da vida. Vejamos o que diz Alexandre Koyré a esse respeito:

A ciência moderna tinha derrubado as barreiras que separavam os Céus e a Terra, que une e unificou o Universo. Isto é verdade. Mas ela fê-lo substituindo o nosso mundo de qualidades e percepções sensíveis, mundo no qual vivemos, amamos e morremos, por outro: o da quantidade, da geometria deificada, no qual há lugar para tudo menos para o homem. Assim, o mundo da ciência - o mundo real - se separou do mundo da vida. Na realidade esses dois mundos estão unidos pela práxis, mas separados por um abismo. É nisto que consiste a tragédia do espírito moderno que desvendou o enigma do Universo, mas para substituí-lo por outro enigma: o de si próprio. (12)

Hamlet foi escrito entre 1599 e 1601, aproximadamente 50 anos após a publicação de De revolutionibus orbium coelestium, de Nicolau Copérnico, e por volta de 30 anos antes da publicação de Dialogo sopra i due massimi sistemi del mondo, de Galileu Galilei. Shakespeare coloca nos lábios do príncipe da Dinamarca a dúvida paralisante das armadilhas do pensamento.

Ser ou não ser - eis a questão. Será mais nobre sofrer na alma pedradas e flechadas do destino feroz ou pegar em armas contra o mar de angústias - e, combatendo-o, dar-Ihe fim? (...) Morrer - dormir - dormir! Talvez sonhar. Aí está o obstáculo! Os sonhos que hão de vir no sono da morte quando tivermos escapado ao tumulto vital nos obrigam a hesitar: e é essa reflexão que dá à desventura uma vida tão longa. (...) E assim o matiz natural da decisão se transforma no doentio pálido do pensamento. E empreitadas de vigor e coragem, refletidas demais, saem de seu caminho, perdem o nome de ação. (13)

A dúvida do príncipe Hamlet irrompe na obra de Shakespeare como chaga do homem moderno, pois sua dúvida não é a mesma que assolava os homens nas tragédias clássicas. "Aqui, a dúvida atroz surge como uma trinca no próprio ser do homem. Entregue às suas forças, o homem acaba perdendo a fé em si mesmo. Ficam a carne, o pensamento... e o sofrimento que o pensamento inflige à carne" (14).

Shakespeare captura a separação entre natureza e cultura na fase embrionária da ciência moderna, cujos desdobramentos são centrais em nossos dias na relação entre cultura e objeto técnico. Não há em Hamlet referência à ciência, mas a força da obra está justamente naquilo que excede a percepção imediata diante da obra literária.

O mesmo ocorre em O sétimo selo (Det sjunde inseglet), filme de 1956, dirigido por Ingmar Bergman: sem mencionar a ciência moderna, já que o filme é ambientado no cenário da Europa medieval, numa época anterior a de Galileu e a de Newton, Bergman tem como pano de fundo desse filme 


\section{Artigos $\odot$ Ensaios}

a dessacralização do conhecimento e o anúncio da ciência como depositária de toda esperança para a dissolução dos mistérios da vida e da morte.

Tal como o personagem de Shakespeare, Antonius Block, cavaleiro recentemente chegado das Cruzadas, encarna todas as dúvidas que as armadilhas que o pensamento nos arma quando rompida a experiência religiosa com o mundo. No início do filme, vemos a cena em que a trupe de artistas dorme numa carroça. O primeiro a despertar é o malabarista Jof: um pernilongo que zunia em seus ouvidos termina picando-o; na transição do mundo dos sonhos para o estado de vigília, Jof esmaga o inseto com uma tapa contra sua própria testa. Antes de jogar o bichinho, contempla-o com um misto de alívio e pesar.

Pensamentos são como insetos impertinentes que giram em nossas mentes. Refiro-me aos pensamentos do tipo que assolavam Hamlet e o perturbado Antonius Block, aos pensamentos que giram em círculos viciosos ao redor da dúvida paralisante que a razão dessacralizada por vezes nos impõe. A atitude de Jof refletirá sua postura diante deste tipo de dúvida que assola seus contemporâneos: ele os jogará fora e sua aflição não durará mais do que o instante de uma picada de pernilongo.

Inspirado no quadro de Albertus Pictor, A morte disputando uma partida de xadrez, o filme de Bergman aposta na racionalidade do jogo de xadrez entre a morte e o cavaleiro como alegoria para as armadilhas que a razão embriagada pela dúvida nos conduz.

O sétimo selo é de 1956 e seu título faz clara referência ao Apocalipse: em meio às feridas abertas pela bomba atômica na Segunda Guerra, na vertigem de sua potência para destruir a vida humana no planeta em minutos, Bergman, num só golpe, sutilmente expõe a degeneração do sagrado com o advento da ciência moderna e traduz a sensação da falibilidade moral do homem para lidar com a dominação da natureza no nível subatômico. A incerteza hamletiana emergida no bojo do florescimento da ciência moderna é atualizada por Bergman na insegurança que as armas nucleares desenvolvidas graças ao avanço da ciência trouxeram especialmente durante a Guerra Fria, tema mais explicitamente retomado por Kubrick nove anos depois pela via da sátira em Dr. Fantástico (Dr. Strangeloveor: how I learnedto stop worryingand love the bomb: 1964).

Talvez ecoem aqui e ali no filme de Bergman trechos do ensaio de D.H. Lawrence, intitulado Apocalipse (15), publicado em 1931, ou quem sabe lampejos do incrível As profecias de Daniel e o Apocalipse de São João (16), texto de Isaac Newton de 1733, erupções no filme que podemos sintetizar na frase de uma canção (17) da música popular brasileira: "lembre-se: quem não vive, tem medo da morte"; ou ainda, já fora do campo perceptivo da ciência, no comentário de uma estudante ao sair da sala onde acabara de ser exibido O sétimo selo: "é a existência inexorável da morte que torna a vida sagrada".

Márcio Barreto é físico e professor da Faculdade de Ciências Aplicadas da Universidade Estadual de Campinas (Unicamp), membro do grupo de pesquisa Conhecimento Tecnologia e Mercado (CTeMe/IFCH/Unicamp) e do Centro de Ciências Humanas e Sociais Aplicadas (CHS/FCA/Unicamp). Email: marcio.barreto@fca.unicamp.br

\section{NOTAS E REFERÊNCIAS BIBLIOGRÁFICAS}

1. Benjamin, W. Walter Benjamin: Obras escolhidas (Magia e técnica, arte e politica). São Paulo: Editora Brasiliense, 1985. pp. 165-196.

2. Os irmãos Max e Emil Skladanowsky criaram um projetor que chamaram de bioscópio, com um sistema mais simples do que cinematógrafo dos irmãos Lumière. Apresentaram os primeiros filmes em Berlim em novembro de 1895, um mês antes da apresentação dos franceses em Paris. É senso comum, no entanto, que o cinematógrafo foi o primeiro aparelho a exibir filmes.

3. Ferreira, P.; Barreto, M. "Fotografia, cinema e velocidade". In: Revista ComCiência, Campinas, v. 93, nov. 2007. Disponível em: <www.comciencia.br/comcien cia/?section=8\&edicao=30\&id=352> Acesso em: 20 mar. 2013 .

4. Merleau-Ponty, M. Fenomenologia da percep̧̧ão. Martins Fontes, 1999. p. 279.

5. Barbaras, R. Investigaçôes fenomenológicas: em direção a uma fenomenologia da vida. Curitiba: Editora da UFPR, 2011. pp. 150-151.

6. Nova, C. "O cinema e o conhecimento da história". In: Olho da História, vol. 3 , pp. 217-233, 1997.

7. Oliveira, B. J. "Cinema e imaginário científico". In: História, Ciências, Saúde Manguinhos. v. 13 (suplemento), p. 144, out. 2006.

8. Deleuze G.Cinema - II: A imagem tempo. Editora Brasiliense, 2005.

9. Tarkovski, A. Esculpir o tempo. Martins Fontes, 1990

10. Cormick, C.: "A clonagem vai ao cinema”. In: História, Ciências, Saúde-Manguinhos, vol. 13, (suplemento), pp. 181-212, out. 2006.

11. Dutra, R. A. "O desencantamento das ciências: estereótipos e ambiguidades das ciências e das tecnociências no cinema e na literatura científica”. 2005. pp.13. 237 f. Tese (doutorado em história social) - PUC/SP, São Paulo. 2001.

12. Koyré, A. Études newtoniennes. Gallimard, 1968.

13. Shakespeare, W. Hamlet. Tradução de Millôr Fernandes. L\&PM, 2011. pp. 66-67.

14. Santos, L. G. "Lautréamont e o desejo de não desejar". In: Novaes, A. (Fundação Nacional de Arte) O desejo. São Paulo: Companhia das Letras, 1990. p. 210.

15. Lawrence, D.H. Apocalipse, seguido de O homem que morreu. Cia das Letras, 1990.

16. Newton, I. As profecias de Daniel e o Apocalipse de São João. São Paulo: Editora Paensamento, 2011.

17. Da canção Chavão abre porta grande, de Itamar Assumpção e Ricardo Guará. Long play Sampa midnight (gravação independente), 1983. 